\title{
Ontologia do jornalismo: trabalho do conhecimento e práxis noticiosa em tempos de crise ${ }^{1}$
}

\section{Rafael Bellan Rodrigues de Souza}

\section{Resumo}

0 texto apresenta as mediações existentes entre 0 trabalho do jornalista e seu produto, a notícia, tendo na crítica ontológica lukacsiana 0 eixo fundamental da compreensão do jornalismo em tempos de crise estrutural do capital. Para tanto, discorre sobre a especificidade do trabalho jornalístico em um contexto de precarização de sua atividade e sua relação com a crise que assola essa forma social de conhecimento. Nesse sentido, ao debatermos a práxis noticiosa e seu valor de uso social, não podemos ignorar os mecanismos de estranhamento instaurados nos momentos de produção, circulação e recepção dessa narrativa, o que nos faz avaliar a atualidade de seu poder de desreificação da realidade.

\section{Palavras-Chave}

Teoria do Jornalismo. Trabalho. Marxismo.

\section{Rafael Bellan Rodrigues de Souza ।}

\section{rafaelbellan@yahoo.com.br}

Doutor em Ciências Sociais pela Universidade Estadual Paulista - UNESP, Brasil. Pós-Doutor pela Escola de Comunicação e Artes da Universidade de São Paulo - USP, Brasil. Professor do Curso de Comunicação Social - Jornalismo e do Programa de Pós-Graduação em Comunicação e Territorialidades da Universidade Federal do Espírito Santo - UFES, Brasil. Pesquisador do Centro de Pesquisa em Comunicação e Trabalho da ECA-USP.

\section{Introdução}

Este artigo se insere na proposta de uma teoria marxista do jornalismo advinda da investigação ontológica desenvolvida por Genro Filho (2012) que, entre outras contribuições de profunda atualidade, apresenta a práxis noticiosa em sua historicidade, apontando as contradições de uma forma social de conhecimento que, embora criada no bojo de uma sociedade capitalista, possui potencialidades que a ultrapassam. 0 jornalismo, nesse sentido, apresenta-se em sua dimensão concreta e histórica, portador de elementos transitórios e ontológicos, sendo que, para além do rastro de seu papel na luta de classes nos momentos conjunturais, faz parte da totalidade humana em sua autorreprodução. Nessa esteira, nossa proposta é estudar esse objeto enquanto parte de um processo, o que demanda ir além da aparência empírica em direção a sua essência, estrutura e dinâmica. Reproduzir teoricamente o concreto enquanto múltiplas determinações, conhecendo as categorias que constituem a articulação interna de um complexo (MARX, 2011a), faz parte da formulação metodológica 
dialética que, não se fixando em regras e

procedimentos, define uma posição ontológica do

sujeito da pesquisa na compreensão realista de

um fenômeno. Para isso, nucleiam-se categorias

como a totalidade, a mediação e a contradição

(NETTO, 2011), bases para um processo de

conhecimento que vai da aparência à essência,

revelando a natureza íntima da dinâmica social no

concreto pensado.

No marxismo, a crítica ontológica pode ser

interpretada como a busca pela constituição

interna do objeto, a própria atividade humana,

sendo que 0 trabalho é a protoforma de todo 0

complexo social, sendo a mediação entre 0 homem

e a realidade objetiva. Dessa forma, "a realidade

social deve ser entendida como totalidade

concreta, como transformação da possibilidade

e probabilidade em liberdade através da criação

e superação permanente de necessidades por

meio de trabalho" (GENRO FILHO, 2012, p. 195).

0 método aplicado por Marx, recuperado na

teoria marxista do jornalismo, pretende expor a

especificidade dos fenômenos dentro do complexo

da sociedade. Tratar de ontologia no marxismo

significa entendê-la como uma ontologia do ser

social, expressão cunhada por György Lukács

(2013) para caracterizar o processo humano

de construção do mundo dos homens por sua

própria autoprodução. A práxis dos homens é

central na elaboração da totalidade social, um complexo de complexos contraditórios, abertos, que se apresenta como estrutura composta pela interação de sujeitos que produzem e reproduzem a vida em sua relação com a natureza.

Em tudo isso, torna-se manifesto um dado ontológico fundamental do ser social: o homem como ser vivo não só biológico, mas ao mesmo tempo como membro trabalhador de um grupo social, não se encontra mais numa relação imediata com a natureza orgânica e inorgânica que 0 circunda, nem mesmo consigo como ser vivo biológico, mas todas essas interações inevitáveis são mediadas pelo medium da sociedade; mais exatamente, como a socialidade do homem representa seu comportamento ativo e prático em relação a seu meio ambiente como um todo, essa mediação ocorre de modo tal que ele não aceita simplesmente o meio ambiente e suas transformações nem se adapta, mas reage ativamente a eles, contrapondo às mudanças do mundo exterior um mundo de sua própria práxis, no qual a adaptação à irrevogabilidade da realidade objetiva e seus novos pores do fim que lhe correspondem formam uma unidade indissociável (LUKÁCS, 2013, p.204).

Pretendemos investigar a dialética existente entre 0 jornalismo enquanto atividade laboral e a perspectiva do seu produto final na conjuntura da crise estrutural do capital (MÉSZÁROS, 2002). Ou seja, racionalizar o contexto histórico processual em que se coloca essa prática, sua dimensão na estrutura subjacente do modo de produção sociometabólico e, depois, refletir sobre sua articulação ontológica, visto que a essencialidade do jornalismo enquanto forma social de 
conhecimento apresenta-se enquanto fenômeno, algo que precisa ser explorado no contexto do capitalismo no século XXI.

Acreditamos que essa tarefa nos exige uma definição clara do trabalho do jornalista, sendo que é na atenção dada à atividade autocriadora do homem e suas mediações que se encontra o nódulo central do projeto marxiano de crítica ontológica e projeto societário. Pois, como aponta Ranieri (2011), tratando da concepção metodológica de Marx, a teoria só ganha materialidade ao levar em conta as relações provenientes do trabalho, visto que, ao abandonar a prática ela pode perder 0 sentido e resvalar na manipulação.

\section{0 trabalho como pôr teleológico}

Antes de buscarmos a melhor caracterização do trabalho do jornalista no interior do sistema sociometabólico do capital, é mister apresentarmos a noção lukacsiana de trabalho, visto que é a mais importante leitura do marxismo enquanto ontologia do ser social. Seria impossível reproduzir aqui, mesmo que superficialmente, a grandiosidade do empenho de Lukács (2013) em desvelar os condicionantes do ser, em seus complexos categoriais mais importantes. Basta, por ora, assinalar a profunda recuperação do trabalho e sua dialética no salto ontológico do homem em sua humanização, como ser criador de seu próprio mundo. A reprodução social é parte constitutiva da dinâmica do homem e alimentadora de sua sociabilidade e se liga ao trabalho de forma inexpugnável, sendo que ele é o modelo de toda a práxis social e das atividades essencialmente humanas.

Seguindo o pensamento de Lukács, "todo fenômeno social pressupõe, de modo imediato ou mediato, eventualmente até remotamente mediato, o trabalho com todas as suas consequências ontológicas" (2013, p.159). A categoria trabalho é considerada 0 elemento fundante do ser social porque é a partir do intercâmbio orgânico com a natureza que o homem se realiza e, diferentemente dos outros animais, cria novas necessidades e possibilidades, proporcionando um processo reprodutivo que requer novos complexos sociais para atender às demandas recém-surgidas. Esses complexos, erguidos por uma nova situação criada pelo trabalho - em que o homem se distancia das barreiras naturais, conforme dizia Marx (2004) -, todavia, também geram novas demandas e devires, e exigem novos complexos, desenvolvendo a totalidade social. As formas históricas de trabalho são criadoras, fundantes, das suas formações sociais específicas. Mesmo assim, vale destacar que a totalidade social não se restringe ao trabalho, mas possui com ele uma relação entre 0 polo fundante e 0 fundado.

Somente 0 trabalho tem, como sua essência ontológica, um claro caráter de transição: ele é, essencialmente, uma inter-relação que pode figurar em pontos determinados da cadeia a que nos referimos, mas antes de tudo assinala a transição, no homem que trabalha, do ser meramente biológico ao ser social (Lukács, 2013, p. 44). 
0 trabalho é apresentado como a objetivação de uma prévia ideação, um pôr teleológico que transforma a natureza seguindo uma intencionalidade subjetiva dada pelos homens. Ou seja, por meio da teleologia uma ordem de cadeias causais é acarretada, constituindo 0 complexo social. A dialética entre teleologia e causalidade representa também a distinção entre sujeito e objeto, sendo o trabalho 0 mediador central entre os dois eixos. 0 pôr teleológico, intencionalidade humana, surge como uma tomada de decisão entre diversas alternativas e, buscando inserir uma finalidade no real, enfrenta outras causalidades dadas na objetividade, inter-relacionando com elas a dinâmica criadora dos complexos sociais. A transformação do potencial advindo da subjetividade em realização depende da dialética entre a causalidade posta e a rede causal determinada na natureza. Como dizia Marx os:

"homens fazem a sua própria história; contudo, não a fazem de livre e espontânea vontade, pois não são eles quem escolhem as circunstâncias sob as quais ela é feita, mas estas Ihes foram transmitidas assim como se encontram" (2011b, p.25).

0 pôr teleológico primário altera a natureza, fazendo com que a consciência crie cadeias de causalidades, alterando a realidade. 0 afastamento das barreiras naturais com 0 desenvolvimento do trabalho mostra a luta do homem para resolver as questões da necessidade e a escassez. Mas há também outro tipo de pôr teleológico, em que a consciência tem um papel crucial na alteração dos pores teleológicos dos outros seres humanos. 0 papel da linguagem nesses complexos é basilar. A finalidade nesse modelo de prévia-ideação é induzir a consciência alheia seguindo um modelo pré-determinado.

(...) 0 objeto desse pôr secundário do fim já não é mais algo puramente natural, mas a consciência de um grupo humano; o pôr do fim já não visa a transformar diretamente um objeto natural, mas, em vez disso, a fazer surgir um pôr teleológico que já está, porém, orientado a objetos naturais; da mesma maneira, os meios já não são intervenções imediatas sobre objetos naturais, mas pretendem provocar essas intervenções por parte de outros homens (LUKÁCS, 2013, p.84).

0 pôr teleológico secundário produziu na sociedade capitalista as mais desenvolvidas formas de divisão do trabalho. As atividades humanas são direcionadas por ideias que definem metas de trabalho, fiscalizam e conduzem, com justificativas ideológicas, 0 modelo de reprodução instaurado. No entanto, não devemos reduzir esse tipo de prévia-ideação pela sua tarefa no modelo estranhado do capital, sendo que ela faz parte da constituição do ser social. As funções da reprodução dos sujeitos e da sociabilidade dependem deste tipo de posição teleológica. Percebe-se a característica comum existente entre o trabalho e a comunicação, já que ambas tem em sua definição a produção consciente e ativa de alterações com base nas intenções subjetivas, e sua finalidade de mudanças nas séries causais do mundo objetivo. 


\section{0 trabalhador jornalista}

Com a divisão do trabalho na ordem de metabolismo social do capital, distingue-se operacionalmente 0 trabalho braçal e 0 trabalho intelectual, assim, o produto final passa a ser "resultado da combinação das operações parciais decompostas" (LUKÁCS, 2013, p.330). Finalidades e meios de um lado, conhecimento de outro. Ao se complexificar, a divisão do trabalho se generaliza amplamente e separa um tipo de trabalho particular, de pores teleológicos secundários, que não elabora produtos decorrentes da natureza, mas que objetiva induzir certos comportamentos no conjunto social. Esse tipo de trabalho no contexto de cooperação complexa (FREDERIC0 e TEIXEIRA, 2008) é imprescindível para a reprodução social e para a organização da produção (ALVES, 2013). 0 foco é a eficácia de funcionamento da maquinaria capitalista. Alguns autores tem denominado esse tipo de trabalho como ideológico e que, quando voltado à formação de sujeitos para 0 sistema, caracterizaria também os jornalistas.

0 trabalho ideológico representa a natureza material de diversas ocupações profissionais no interior da divisão social do trabalho. Por exemplo, ele caracteriza o trabalho de formação e informação (professores e jornalistas), 0 trabalho de regulação e normatividade (juízes e policiais), o trabalho de convencimento (publicitários), o trabalho do cuidado (médicos, enfermeiros, psicólogos e assistentes sociais) etc (ALVES, 2013, p. 187).
Rejeitando uma visão empirista do trabalho ${ }^{2}$, busca-se afirmar as dimensões do trabalho humano numa mirada sócio-ontológica, ressaltando o pôr teleológico secundário. 0 jornalista, ao atuar na criação de produtos voltados à formação intelectual dos leitores teria uma dimensão certamente semelhante ao explicitado por Alves (2013). Contudo, concordamos com Fuchs (2015) que os produtos comunicacionais não necessariamente se tornam ideologia, eles somente ganhariam essa dimensão quando incidissem na consciência prática dos homens voltada à luta de classes. Essa noção de ideologia também se relaciona com a exposta por Lukács (2013) e Mészáros (2004).

Até por uma proximidade com a definição do jornalismo como forma social de conhecimento, e pelo termo ideologia ainda estar muito carregado do sentido de falsa consciência, preferimos a caracterização dada por Huws (2013) de trabalhador do conhecimento, enfoque que tem evidência também nos estudos de Mosco (2012). Isso não significa adesão nem à ideia de "fim do trabalho" e aceitação acrítica do conhecimento como única fonte de valor, nem à tese idealista do trabalho imaterial. A autora aponta alguns tipos de trabalhos conectados ao conhecimento: os ligados a processos de elaboração (desenvolvedores softwares, projetistas etc) e processos de distribuição (call centers, etc), e também os criativos, produtores de saberes novos. 
Então, existe também outro tipo de trabalho do conhecimento, o qual poderíamos chamar de trabalho "criativo" ou "original" (alguns dos quais podem ter contribuições, com ou sem reconhecimento, dos trabalhadores de "processo"), que gera novo capital intelectual, na forma de ideias, design, programas, ou produtos intelectuais mais definíveis (se não tangíveis), tais como letras, música, ou imagens. A contribuição feita por este trabalho é mais difícil de calcular. As ideias podem ser apropriadas de uma força de trabalho remunerada (na maioria dos países, a posse da propriedade intelectual produzida pelo empregado é automaticamente designada ao empregador) (HUWS, 2013, p. 33).

Esse setor também compreende os frellancers, os trabalhadores individuais, as organizações independentes. 0 fato é que os trabalhadores do conhecimento criativo produzem conteúdos culturais em uma realidade de desenvolvimento da tecnologia de compartilhamento de conteúdos.

Mesmo os jornalistas estando nesse tipo de atividade, não necessariamente eles são autores criadores autônomos de suas narrativas.

0 trabalhador do conhecimento geralmente ocupa uma posição intermediária na qual poderia ser visto como a cadeia alimentar do conhecimento. As ideias não vêm de lugar nenhum: elas podem ser copiadas, consciente e inconscientemente, dos outros; elas podem trazer consigo o que foi aprendido com os professores, livros ou por observações de pessoas que não se consideram criativas; ou, ainda, as ideias podem surgir das interações de um grupo de pessoa trabalhando juntas como uma equipe (HUWS, 2013, p.38).

Preferimos não debater aqui a categoria de cibertariado da autora, direcionando-nos mais à especificidade do jornalista como um trabalhador que produz uma forma de conhecimento, sujeito de pores teleológicos secundários, atuando numa esfera de complexidade cooperativa que, para materializar seu produto, depende de outros trabalhadores (relacionados ao trabalho de pôr teleológico primário). A relevância do estudo de Huws (2013) está em perceber a relação da tecnologia e da divisão do trabalho com a ordem do capital, sendo que a precarização e a condição de proletariedade não os poupa. As mudanças no mundo do trabalho modificaram a dinâmica dos jornalistas, seu perfil, sua identidade, e também sua rotina produtiva, bem como suas práticas (FIGAR0, 2014). Acreditamos que o jornalista é parte da classe-que-vive-do-trabalho (ANTUNES, 1999), pois, embora multifacetada e com morfologia bastante complexa, o repórter é executor de um tipo de trabalho abstrato, parte da dimensão global de reprodução do capital. A década de 90 potencializou a mudança desse perfil na classe trabalhadora.

(...) a divisão do trabalho evoluiu até um ponto onde uma parte substancial da força de trabalho está engajada em trabalho "não-manual" - na geração ou processamento de "informação" (embora este trabalho, todavia, envolva o corpo em uma série de atividades físicas, tal como digitar, que tem implicações para seu bem-estar fisiológico). 0 desenvolvimento da tecnologia da computação tornou possível que essa informação fosse digitalizada e alguns aspectos de seu processamento fossem automatizados, bem como o desenvolvimento da tecnologia de comunicações possibilitou que essa informação fosse transmitida de um lugar para outro com grande rapidez e a um custo muito baixo (HUWS, 2013, p. 35). 
0 estranhamento ${ }^{3}$, contudo, generaliza-se, no trabalho do conhecimento, principalmente pela falta de conexão existente entre as particularidades dessas atividades laborais, bem como sua intricada divisão internacional. Um aspecto fundamental é 0 contexto de esvaziamento cada vez mais amplo dos conteúdos dos produtos intelectuais, cuja inspiração neopositivistas e irracionalistas já haviam sido antevistas por Lukács (2009) no conceito de decadência ideológica. Com o complexo total da ordem do capital em crise estrutural ${ }^{4}, 0$ trabalho do conhecimento passa por uma crise em dois aspectos principais: na atividade estranhada e precarizada, consequência da negação do sentido do trabalho pela produção do capital e na sociabilidade corroída pela barbárie social e miséria ideológica.

\section{Práxis noticiosa dos trabalhadores da comunicação}

Genro Filho (2012) apresenta as bases ontológicas para expressar, em débito com uma leitura das reflexões estéticas lukacsianas, a essência do jornalismo: uma forma social de conhecimento cristalizada no singular. Porém, assim como nem toda forma de arte cumpre um papel de conhecimento e nem toda a ciência é capaz de revelar a concreticidade do mundo dos homens, nem toda produção noticiosa cumpre seu papel enquanto conhecimento crítico do mundo, aquele capaz de combater o véu da reificação capitalista.

Entendemos reificação como a aparência de relações entre coisas que as relações sociais adquirem na sociedade do capital, sendo ela uma das principais formas de estranhamentos engendradas por essa ordem exploratória. Junto ao fetiche de mercadoria e ao estranhamento dos próprios trabalhadores com o resultado de seu trabalho e, não obstante, com o próprio gênero humano, vemos que as mudanças tecnológicas no campo da comunicação, vista por muitos como um momento de conhecimento disseminado, esclarecido e amplo, tem gerado cada dia mais ocultamento dos processos sociais concretos.

Com a crise do jornalismo, expressão da precarização intensiva do trabalhador da

A ideia de que o desenvolvimento das capacidades humanas não acarreta necessariamente um desenvolvimento da personalidade humana e de que pode até mesmo rebaixá-la faz parte do pensamento lukacsiano.

Nesta crise, os limites absolutos do sistema são desafiados para garantir a recuperação da queda da taxa de lucros, que se intensifica desde os anos 70. Ela manifesta-se em quatro temas principais: primeiro, ela possui caráter universal, não se restringindo a uma esfera particular, como algum setor específico de trabalho, por exemplo; em segundo lugar, 0 alcance da crise estrutural é global, não se limita a um certo número de países; terceiro, ela, mais do que cíclica, atinge uma escala temporal permanente, irrecuperável; por último, em quarto lugar, a crise possui um desenvolvimento sub-reptício, rastejante, ou seja, entra em contraste com as alterações do sistema vistas no passado, embora reserve para o futuro grandes convulsões, dada a constante destruição dos aparatos de controle das contradições do capitalismo. A crise se inicia no pósGuerra e se intensifica a partir da década de 70. Para Mészáros (2002), essa crise estrutural é inseparável da ativação dos limites intransponíveis do capital, com as consequências mais destrutivas para o futuro. 
comunicação e da ampla esfera de divulgação de informações, a mercadoria notícia passa por questionamentos. Já reificada em sua fase "moderna" e "analógica", agora, com a possibilidade de qualquer um se tornar produtor de informação - os chamados prodsumidores de Ramonet (2012) - o senso comum singularizado espontaneamente tem inundado a esfera midiática. 0 valor de uso social dessa mercadoria passa por um terremoto, sendo ainda preliminar avaliar seus impactos. Contudo, com a crescente parcela explosiva de disponibilidade de informação, e com a proximidade dessas com as notícias enviesadas e superficiais agilizadas pelos jornalistas da imprensa burguesa - que também consegue explorar claramente 0 sistema digital, segundo Moraes (2016) - a forma social de conhecimento jornalismo torna-se um bem cada dia menos disponível.

A práxis noticiosa dos trabalhadores do conhecimento permanece alvo dos esquemas burgueses de manipulação já consagrados desde o nascimento dessa prática, somando-se a isso a insanável ampliação do espaço de infotenimento, notícias voltadas à diversão e lazer. Para além dessas dificuldades, o estranhamento do jornalista e do público se intensificou, sendo que eles sofrem na esfera do trabalho a captura de sua subjetividade e a corrosão de seus valores morais (ALVES, 2011) (SENNET, 2009).

Em busca de maior liberdade, muitos desses trabalhadores se tornam empreendedores sociais, mas, além de continuarem participando da mesma ordem complexa de reprodução do capital, assumindo muitas vezes o papel de homemempresa (DARDOT e LAVAL, 2016), eles enfrentam novas dificuldades como o muro legal burguês e a sustentação financeira. A precariedade também os atinge de forma brutal, dilacerando até os jornalistas mais bem intencionados.

Expande-se a produção de singularidades reificadas cimentadas no senso comum, com sujeitos incrustrados na pseudo-concreticidade (KOSIK, 2002). A explosão da massa de mídias abre contraditoriamente espaço para a liberdade de elaboração dos mais diversos conteúdos, mas, por ser capitaneada pela classe dominante e não resultar da tarefa revolucionária dos trabalhadores, chega em um momento onde não há o preparo político para explorar suas potencialidades conforme vaticinava Enzensberger (2006) nos anos 70. Talvez ai esteja o maior desafio do projeto marxiano de desenvolvimento humano omnilateral: a derrocada de cima a baixo de um sistema e sua substituição por um modo de reprodução social orgânico capaz de ser controlado pelos produtores livremente associados.

Alguns sintomas da crise estrutural do capital (MÉSZÁROS, 2002), a barbárie social, a decadência ideológica multiplicada pelo pósmodernismo e 0 irracionalismo individualista, afetam o papel da notícia no mundo contemporâneo. Quando o sistema alcança seus 
limites absolutos, com a catástrofe e a exceção tornadas regras cotidianas, há o desgaste das forças capazes de enfrentá-los, entre eles 0 jornalismo crítico-emancipatório, que, quando realista, pode permitir a elevação rumo há um cotidiano articulado à comunidade humana e seus desafios históricos.

Uma ontologia do jornalismo precisa articular uma reflexão sobre a produção material da mercadoria notícia, parte do pôr teleológico secundário e, portanto, distinto de um produto qualquer, tendo como foco o trabalho jornalístico (parte dos trabalhadores do conhecimento, ramo da classeque-vive-do-trabalho) e o contexto econômico mais amplo da crise estrutural do sistema de reprodução sociometabólico do capital.

A singularidade reificada amplificada nas redes sociais e na esfera digital tem modificado a geração de valor na mercadoria notícia, sendo pretexto para constantes reestruturações no trabalho dos jornalistas, precarizando ainda mais a rotina produtiva dos trabalhadores do conhecimento e redimensionando 0 estranhamento desses sujeitos sociais. "Passaralhos" e enxugamentos salariais são a tônica típica da expressão da luta de classes entre capitalistas e trabalhadores. Com a digitalização, a tecnologia torna-se álibi da superexploração do trabalho, em que 0 desemprego crônico se revela como parte de uma dinâmica em que 0 exército de reserva garante espaço para 0 achatamento salarial.
Embora a disseminação ampla da imediaticidade dos fluxos informacionais reificados amplie o estranhamento, a eliminação total de compreensões críticas do mundo jamais será viabilizada, dado que as contradições reais do sistema afloram em progressão espantosa. Um jornalismo como forma social de conhecimento crítico-emancipatório nunca foi tão necessário, mas a sua articulação social encontra um ambiente novo para ser divulgado. Os processos de sua constituição devem passar também pela superação dos condicionantes materiais e objetivos que impedem sua realização. A superação do trabalho estranhado, mesmo que ocorra em algumas situações limitadas, implica, certamente, um grau maior de transformações radicais na sociedade do capital.

0 potencial educativo da práxis noticiosa se aproxima da construção de uma ideologia emancipatória, visto que incide na subjetividade dos sujeitos sociais. Assim, o jornalismo como forma social de conhecimento também pode ser visto, como a educação, enquanto "0 desenvolvimento progressivo da consciência socialista integrante à vida dos indivíduos sociais em sua estreita interação com seu ambiente social historicamente em transformação" (MÉSZÁR0S, 2008, p. 102). Assim, seguindo o legado de Genro Filho (2012), muito bem sistematizado também por Pontes (2015), o jornalismo pode ser uma atividade indispensável à superação dos graves problemas gerados no horizonte dessa ordem sociometabólica. 


\section{Considerações Finais}

Constata-se, assim, uma miríade de problemas que fazem parte da nova condição de produção jornalística no século XXI. 0 rótulo crise tem sido usado para sintetizar o momento de incertezas referentes a esta prática social. Esta crise possui amarras bem cimentadas com uma dinâmica maior de indefinições que perpassam o próprio metabolismo social, apresentando epifenômenos de ordem econômica, política, trabalhista, variáveis que impactam na sociabilidade humana e resvalam, inegavelmente, na subjetividade dos trabalhadores. As formas de conhecimento, como o jornalismo, sofrem o impacto dessas mudanças, principalmente com as aceleradas alterações nas suas engrenagens. 0 jornalista é 0 ser produtor da informação noticiosa e os desafios e obstáculos que se colocam a sua frente dia após dia tendem a achatá-lo como um mero executor de tarefas estranhadas.

\section{0 fortalecimento das fontes de informação} enquanto protagonistas das pautas tem colocado os relações públicas e os assessores de imprensa como agentes de notícia. 0 enfraquecimento do jornalista nesses processos é inegável. Com a disponibilidade de informação e relatórios que inundam as esferas de produção de conteúdo, o perfil que tem se construído é mais o de um organizador de informação do que a de um profissional responsável pela apuração e divulgação de acontecimentos de relevo social. Com a facilidade em adquirir conteúdos, os empresários do setor aproveitam para diminuir custos e maximizar lucros com 0 enxugamento de trabalhadores. A passividade dos autônomos, motivadas por adesão ideológica, mas também por necessidade de sobrevivência concreta, proporciona maior controle dos empresários, que reestruturam diariamente 0 parque produtivo no sentido de cimentar seu poder em um negócio fluído e incerto. Alimentar a grande máquina informativa tornou-se a tarefa desses operários da notícia, mas a abundância e gratuidade com que um exército de produtores de conteúdo despejam na rede suas informações, fragilizam o status e a credibilidade do jornalista. É um "mar de narradores" (NEVEAU, 2010, p. 40) que desmorona o lugar social que o jornalismo já ocupou no passado. Os referenciais norteadores da profissão são substituídos por eficiência em agradar clientes e atender nichos de mercado cada dia mais descompromissados com conhecimentos capazes de mudar a vida social.

Esta materialidade contraditória e precária que afeta desde a subjetividade do trabalhador, como demonstramos anteriormente, até seus produtos, corrobora as dificuldades vividas pela imprensa. Todavia, o fluxo constante de informação disponíveis e a ascensão da "massa de mídias" (RAMONET, 2012) têm motivado inúmeros projetos jornalísticos. Longe dos conglomerados, muitos tentam produzir informações noticiosas nesse espaço que se abre nas últimas décadas. Rearticulando outras lógicas, com predominância para 0 colaboracionismo, essas iniciativas 
podem tanto ser outra roupagem de um empreendedorismo corroído pela subjetividade estranhada dos neossujeitos (DARDOT e LAVAL, 2016), como germens de iniciativas que se direcionem a construção de um jornalismo realista, crítico-emancipatório - aquele aguçador da percepção desreificadora dos fatos.

A resposta sobre 0 tom potencial dessas novas formas de produção jornalística, que afloram no cenário digital, está inscrito nas engrenagens dessa produção, mas também no papel ideológico e ontológico que perfaz os sentidos que são dispostos e enquadrados nas matérias. Alternativos, independentes, populares ou ativistas, esses coletivos interessados na produção noticiosa se apresentam muito mais como uma saída militante para o desmanche do monopólio da fala dos grandes veículos, do que estratégias realmente sustentáveis que apontem para uma saída anticapitalista e comunal para 0 sociometabolismo da barbárie (ALVES, 2011).

De toda forma, 0 encontro entre saídas gestionárias coletivistas, no espírito de uma horizontalidade maior entre os sujeitos, bem como a posição em apoio de causas progressistas consegue lançar esses grupos na luta pelo sentido em tempos de crise. Materiais de matriz crítica podem ser encontrados nesses experimentos jornalísticos, principalmente nos que corajosamente abraçam o resgate da reportagem. 0 papel investigativo da práxis noticiosa também é mantido vivo, embora um balanço sobre sua capacidade desreificadora ainda mereça maior debate. Parece evidente que os conglomerados de mídia agora dividem espaço com uma dispersão molecular de agentes comunicativos, falta, contudo, discutir até que ponto estas saídas são satélites dos mass media ou realmente propostas sólidas de uma mídia contra-hegemônica.

Pela via da apreensão do movimento processual da realidade presente em fatos jornalísticos, 0 repórter tem uma missão nas disputas pela hegemonia. Construindo e refletindo os acontecimentos, a práxis noticiosa tem uma força indispensável na delimitação de uma ideologia emancipatória, ou seja, pode colaborar para as estratégias alternativas capazes de estimular 0 crescimento do controle das classes subalternas sobre o metabolismo social. Ao fabricar consciências para outra forma de gestão da produção material, ao preparar para a leitura crítica da realidade, a defesa do jornalismo é parte da bandeira por uma sociedade emancipada. Isso porque, concordando com Neveau (2010), "as sociedades humanas são também quebracabeças a serem compreendidos, com experiências diferentes a serem tornadas visíveis, injustiças a serem questionadas, metas compartilhadas a serem identificadas" (p. 53).

0 jornalismo possível e necessário pode até assumir o compromisso da "precisão" (MEYER, 2007) mas sem 0 horizonte marxista da dialética materialista e da crítica ontológica, 0 fantasma da conduta neopositivista burguesa 
(LUKÁCS, 2013) pode bater à porta. 0 equilíbrio entre a velocidade, a checagem disciplinada e a criatividade na apresentação formal do conteúdo informativo, pode ganhar folego extra com a busca das mediações e contradições entre as expressões singulares, particulares e universais dos acontecimentos. 0s dispositivos tecnológicos e os recursos humanos são braços valiosos de uma ideia da profissão que precisa ser resgatada: a noção heroica do agente social repórter. As reportagens de Joe Sacco (2000), iniciativas jornalísticas presentes na revista americana Jacobin, no jornal francês Le Monde Diplomatique, as matérias brasileiras online do Correio da Cidadania, Brasil de Fato e do recente Esquerda Diário, para citar apenas alguns, ilustram esse tipo de comportamento crítico.

0 realismo somado à postura militante, abraçada à causa do gênero humano, cujo teor de classe jamais pode ser ignorado, implica o combate nas instâncias de produção da notícia, mas também a necessidade de luta organizada pela superação das mediações de segunda ordem do capital (MÉSZÁROS, 2002). A práxis noticiosa de vertente emancipatória, desta feita, congrega experimentações comunais (ante a razão neoliberal concorrencial e individualista) com militância realista em prol do desnudamento das contradições do sistema. Para além do papel cultural e político louvável das mídias radicais alternativas, não podemos abandonar a necessidade de um jornalismo também radical. Este vai à raiz das questões, esclarecendo, via singularidade dos fatos, um público que carece de informações capazes de direcioná-lo para uma vida plena de sentido, algo só possível quando se luta.

\section{Referências:}

ALVES, Giovanni. Dimensões da Precarização do

Trabalho: ensaios de Sociologia do Trabalho. Bauru: Canal 6, 2013.

Trabalho e Subjetividade: 0 espírito do toyotismo na era do capitalismo manipulatório. São Paulo: Boitempo, 2011.

ANTUNES, Ricardo. 0s sentidos do trabalho: ensaio sobre a afirmação e a negação do trabalho. São Paulo: Editora Boitempo, 1999.

\section{ENZENSBERGER, Hans Magnus. Elementos para} uma teoria dos meios de comunicação. São Paulo: Conrad Editora, 2003.

DARDOT, Pierre. e LAVAL, Christian. A nova razão do mundo: ensaio sobre a sociedade neoliberal. São Paulo, Editora Boitempo, 2016.

FIGAR0, Roseli. Jornalismos e Trabalho de

Jornalistas: desafios para as novas gerações no século XXI. Revista Parágrafo. v. 2, n. 2, 2014.

FREDERIC0, Celso; TEIXEIRA, Francisco. Marx no

Século XXI. São Paulo: Cortez, 2008.

FUCHS, Christian. Georg Lukács as a

Communications Scholar: Cultural and Digital Labour in the Context of Lukács' Ontology of Social Being. In Media, Culture \& Society, first published on december 23, 2015.

GENRO FILHO, Adelmo. 0 segredo da pirâmide: para uma teoria marxista do jornalismo. Florianópolis: Editora Insular, 2012.

HUWS, Ursula. Mundo material: o mito da economia imaterial. Revista Outubro. n. 21. $2^{\circ}$ semestre de 2013. 
LUKÁCS, György. Para uma ontologia do ser social

II. São Paulo: Boitempo Editorial, 2013.

. Marxismo e teoria da literatura. São Paulo: Expressão Popular, 2009.

MARX, Karl. Grundrisse. São Paulo: Boitempo Editorial, 2011a.

Manuscritos Econômicos-Filosóficos. São

Paulo: Boitempo Editorial, 2004.

. 018 Brumário de Luís Bonaparte. São

Paulo: Boitempo Editorial, 2011b.

MÉSZÁROS, István. Educação para além do capital. São Paulo: Boitempo, 2008.

0 poder da ideologia. São Paulo: Boitempo

Editorial, 2004.

Para além do capital. São Paulo: Boitempo

Editorial, 2002.

MEYER, Philip. 0s jornais podem desaparecer?

Como salvar o jornalismo na era da informação. São

Paulo: Contexto, 2007.

MORAES, Dênis de. Crítica da Mídia e Hegemonia

Cultural. Rio de Janeiro: Mauad X, 2016.

MOSC0, Vicente. Marx is back, but which one? On knowledge labour and media practice. In: FUCHS, Christian and MOSC0, Vicente. Marx is back: the importance of Marxist theory and research for critical communication studies today. triple C, v. 10 n. 2, 2012.

NETTO, José Paulo. Introdução ao estudo do método de Marx. São Paulo: Expressão Popular, 2011.

NEVEAU, Érik. As Notícias sem Jornalistas: uma ameaça real ou uma história de terror? Brazilian Journalism Research, v.6, n.1, 2010.

PONTES, Felipe Simão. Adelmo Genro Filho e a Teoria do Jornalismo. Santa Catarina: Editora Insular, 2015.
RAMONET, Ignácio. A explosão do jornalismo:

das mídias de massas à massa de mídias. São Paulo:

Publisher Brasil, 2012.

RANIERI, Jesus. Trabalho e Dialética: Hegel, Marx e a teoria social do devir. São Paulo: Editora Boitempo, 2011.

SACC0, Joe. Palestina: uma nação ocupada. São Paulo: Conrad, 2000. 


\begin{tabular}{|c|c|}
\hline $\begin{array}{l}\text { Ontology of journalism: } \\
\text { knowledge work and news } \\
\text { praxis in times of crisis }\end{array}$ & $\begin{array}{l}\text { Ontología del periodismo: } \\
\text { trabajo del conocimiento y praxis } \\
\text { noticiosa en tiempos de crisis }\end{array}$ \\
\hline $\begin{array}{l}\text { Abstract } \\
\text { The text presents the existing mediations between } \\
\text { the work of the journalist and his product, the } \\
\text { news, having in ontological criticism of Lukács } \\
\text { the fundamental axis of the understanding of } \\
\text { journalism in capital structural crisis times. To do } \\
\text { so, it discusses the specificity of journalistic work } \\
\text { in a context of precariousness of its activity and its } \\
\text { relation to the crisis that plagues this social form } \\
\text { of knowledge. In this sense, when discussing news } \\
\text { praxis and its value of social use, we can not ignore } \\
\text { the mechanisms of estrangement established in the } \\
\text { moments of production, circulation and reception of } \\
\text { this narrative, which makes us evaluate the actuality } \\
\text { of its power to desreification of reality. } \\
\text { Keywords } \\
\text { Theory of Journalism. Work. Marxism. }\end{array}$ & $\begin{array}{l}\text { Resumen } \\
\text { El texto presenta las mediaciones existentes entre } \\
\text { el trabajo del periodista y su producto, la noticia, } \\
\text { teniendo en la crítica ontológica lukacsiana el eje } \\
\text { fundamental de la comprensión del periodismo } \\
\text { en tiempos de crisis estructural del capital. Para } \\
\text { ello, discurre sobre la especificidad del trabajo } \\
\text { periodístico en un contexto de precarización de } \\
\text { su actividad y su relación con la crisis que asola } \\
\text { esa forma social de conocimiento. En ese sentido, } \\
\text { al debatir la praxis noticiosa y su valor de uso } \\
\text { social, no podemos ignorar los mecanismos de } \\
\text { extrañamiento instaurados en los momentos de } \\
\text { producción, circulación y recepción de esa narrativa, } \\
\text { lo que nos hace evaluar la actualidad de su poder de } \\
\text { desreificación de la realidad. } \\
\text { Palabras clave }\end{array}$ \\
\hline
\end{tabular}




\section{Expediente}

A revista E-Compós é a publicação científica em formato eletrônico da Associação Nacional dos Programas de Pós-Graduação em Comunicação (Compós). Lançada em 2004, tem como principal finalidade difundir a produção acadêmica de pesquisadores da área de Comunicação, inseridos em instituições do Brasil e do exterior.

\section{E-COMPÓS I www.e-compos.org.br I E-ISSN 1808-2599}

Revista da Associação Nacional dos Programas de Pós-Graduação em Comunicação. Brasília, v.20, n.3, set./dez. 2017. A identificação das edições, a partir de 2008 , passa a ser volume anual com três números. Indexada por Latindex I www.latindex.unam.mx

\section{CONSELHO EDITORIAL}

Ada Cristina Machado Silveira, Universidade Federal de Santa Maria, Brasil Alda Cristina Silva da Costa, Universidade Federal do Pará, Brasil Alfredo Luiz Paes de Oliveira Suppia, Universidade Estadual de Campinas, Brasil Ana Regina Barros Rego Leal, Universidade Federal do Piauí, Brasil Ana Carolina Rocha Pessôa Temer, Universidade Federal de Goiás, Brasil André Luiz Martins Lemos, Universidade Federal da Bahia, Brasil Angela Cristina Salgueiro Marques, Universidade Federal de Minas Gerais, Brasil Ângela Freire Prysthon, Universidade Federal de Pernambuco, Brasil Antonio Carlos Hohlfeldt, Pontifícia Universidade Católica do Rio Grande do Sul, Brasil Arthur Ituassu, Pontifícia Universidade Católica do Rio de Janeiro, Brasil

Bruno Campanella, Universidade Federal Fluminense, Brasil

Cláudio Novaes Pinto Coelho, Faculdade Cásper Líbero, Brasil Cárlida Emerim, Universidade Federal de Santa Catarina, Brasil Carlos Eduardo Franciscato, Universidade Federal de Sergipe, Brasil Danilo Rothberg, Universidade Estadual Paulista, Brasil Denise Tavares da Silva, Universidade Federal Fluminense, Brasil Diógenes Lycarião, Universidade Federal do Ceará, Brasil Eduardo Vicente, Universidade de São Paulo, Brasil Eliza Bachega Casadei, Escola Superior de Propaganda e Marketing - SP, Brasil Eneus Trindade, Universidade de São Paulo, Brasil

Erick Felinto de Oliveira, Universidade do Estado do Rio de Janeiro, Brasil Erly Vieira Júnior, Universidade Federal do Espírito Santo, Brasil Francisco de Assis, FIAM-FAAM Centro Universitário, Brasi

Francisco Elinaldo Teixeira, Universidade Estadual de Campinas, Brasil Francisco Gilson R. Pôrto Jr., Universidade Federal do Tocantins, Brasil Frederico de Mello Brandão Tavares, Universidade Federal de Ouro Preto, Brasil Gabriela Reinaldo, Universidade Federal do Ceará, Brasil Gilson Vieira Monteiro, Universidade Federal do Amazonas, Brasil Gustavo Daudt Fischer, Universidade do Vale do Rio dos Sinos, Brasi Itania Maria Mota Gomes, Universidade Federal da Bahia, Brasil Jiani Adriana Bonin, Universidade do Vale do Rio dos Sinos, Brasil José Afonso da Silva Junior, Universidade Federal de Pernambuco, Brasil José Luiz Aidar Prado, Pontifícia Universidade Católica de São Paulo, Brasi Josette Maria Monzani, Universidade Federal de São Carlos, Brasi Juçara Gorski Brittes, Universidade Federal de Ouro Preto, Brasil
Juliana Freire Gutmann, Universidade Federal da Bahia, Brasil Laura Loguercio Cánepa, Universidade Anhembi Morumbi, Brasil Leonel Azevedo de Aguiar, Pontifícia Universidade Católica do Rio de Janeiro, Brasil Letícia Cantarela Matheus, Universidade do Estado do Rio de Janeiro, Brasil Luciana Coutinho Souza, Universidade de Sorocaba, Brasil Maria Ataide Malcher, Universidade Federal do Pará, Brasil Maria Elisabete Antonioli, Escola Superior de Propaganda e Marketing - SP, Brasil Maria das Graças Pinto Coelho, Universidade Federal do Rio Grande do Norte, Brasil Marialva Carlos Barbosa, Universidade Federal do Rio de Janeiro, Brasil Marcel Vieira Barreto Silva, Universidade Federal da Paraíba, Brasil Marcia Tondato, Escola Superior de Propaganda e Marketing, Brasil Marli Santos, Universidade Metodista de São Paulo, Brasil

Márcio Souza Gonçalves, Universidade do Estado do Rio de Janeiro, Brasil Mauricio Mario Monteiro, Universidade Anhembi Morumbi, Brasil Mayka Castellano, Universidade Federal Fluminense, Brasil

Mozahir Salomão Bruck, Pontifícia Universidade Católica de Minas Gerais, Brasil Nisia Martins Rosario, Universidade Federal do Rio Grande do Sul, Brasil Paolo Demuru, Universidade Paulista, Brasil

Paula Melani Rocha, Universidade Estadual de Ponta Grossa, Brasil Potiguara Mendes Silveira Jr, Universidade Federal de Juiz de Fora, Brasil Priscila Ferreira Perazzo, Universidade Municipal de São Caetano do Sul, Brasil Rafael Cardoso Sampaio, Universidade Federal do Paraná, Brasil Rafael Tassi Teixeira, Universidade Tuiuti do Paraná, Brasil Regiane Lucas Garcês, Universidade Federal de Minas Gerais, Brasil Regiane Regina Ribeiro, Universidade Federal do Paraná, Brasil Renata Pitombo Cidreira, Universidade Federal do Recôncavo da Bahia, Brasil Renato Essenfelder, Escola Superior de Propaganda e Marketing, Brasil Roberto Elísio dos Santos, Universidade Municipal de São Caetano do Sul, Brasil Rodolfo Rorato Londero, Universidade Estadual de Londrina, Brasil Roseli Figaro, Universidade de São Paulo, Brasil

Simone Maria Andrade Pereira de Sá, Universidade Federal Fluminense, Brasil Sofia Cavalcanti Zanforlin, Universidade Católica de Brasília, Brasil Sônia Caldas Pessoa, Universidade Federal de Minas Gerais, Brasil Tatiana Oliveira Siciliano, Pontifícia Universidade Católica do Rio de Janeiro, Brasil Thaïs de Mendonça Jorge, Universidade de Brasília, Brasil

Valquiria Michela John, Universidade Federal do Paraná, Brasil

\section{CONSELHO CIENTÍFICO}

Cristiane Freitas Gutfreind, Pontifícia Universidade Católica do Rio Grande do Sul, Brasil | Eduardo Antônio de Jesus, Universidade Federal de Minhas Gerais, Brasil I Eduardo Morettin, Universidade de São Paulo, Brasil I Irene de Araújo Machado, Universidade de São Paulo, Brasil I Miriam de Souza Rossini, Universidade Federal do Rio Grande do Sul, Brasil

\section{COMISSÃO EDITORIAL}

Eduardo Antonio de Jesus, Universidade Federal de Minas Gerais, Brasil I Igor Pinto Sacramento, Universidade Federal do Rio de Janeiro, Brasil I Kelly Cristina de Souza Prudencio, Universidade Federal do Paraná, Brasil I Osmar Gonçalves dos Reis Filho, Universidade Federal do Ceará, Brasil I Rafael Grohmann, FIAMFAAM - Centro Universitário, Brasil (editor associado)

\section{CONSULTORES AD HOC}

Afonso de Albuquerque, Universidade Federal Fluminense, Brasil I Francisco Rüdiger, Pontifícia Universidade Católica do Rio Grande do Sul, Brasil I Gislene da Silva, Universidade Federal de Santa Cataria, Brasil I Luiz Cláudio Martino Universidade de Brasília, Brasil I Magali Nascimento Cunha, Universidade Metodista de São Paulo, Brasil I Márcia Franz Amaral, Universidade Federal de Santa Maria, Brasil I Tania Marcia Cezar Hoff, Escola Superior de Propaganda e Marketing, Brasil I Raquel Paiva, Universidade Federal do Rio de Janeiro, Brasil

\section{EQUIPE TÉCNICA}

ASSISTENTE EDITORIAL Márcio Zanetti Negrini I REVISÃO DE TEXTOS Melina Santos I EDITORAÇÃO ELETRÔNICA Roka Estúdio
COMPÓS I www.compos.org.br

Associação Nacional dos Programas de Pós-Graduação em Comunicação

Presidente

Marco Roxo

Programa de Pós-Graduação em Comunicação - UFF marcos-roxo@uol.com.br

Vice-Presidente

Isaltina Gomes

Programa de Pós-Graduação em Comunicação - UFPE isaltina@gmail.com

Secretária-Geral

Gisela Castro

Programa de Pós-Graduação em Comunicação

e Práticas de Consumo - ESPM

castro.gisela@gmail.com

CONTATO I revistaecompos@gmail.com 